\title{
REVISITANDO LOS DOCUMENTOS CLAVES DE LA PAC EN BUSQUEDA DE UNA PERSPECTIVA DE GÉNERO: LA CONFERENCIA DE STRESSA
}

\section{Tomás García Azcárate* ${ }^{\mathrm{a} *}$, Alicia Langreo Navarro ${ }^{\mathrm{b}}$}

${ }^{a}$ Vice-Director del Instituto de Economía, Geografía y Demografía (IEGD-CSIC) e investigador asociado del CEIGRAM, Madrid, E-mail: tomasgarciaazcarate@gmail.com ${ }^{b}$ Directora de Sabora, S.L. E-mail: alangreonavarro@gmail.com

\section{Resumen}

Son muy escasos los estudios existentes que abordan la Política Agraria Común (PAC) desde una perspectiva de género. Esta Comunicación es el primer resultado de una línea e investigación que revisita los textos fundadores de la PAC desde esta perspectiva.

Los documentos de la Conferencia de Stressa (Julio 1958) son los que mejor recopilan el pensamiento de los padres fundadores de la primera política común de la que se dotó la naciente Comunidad Económica Europea. Los resultados de una primera búsqueda informática fue muy decepcionantes con lo que se buscó manualmente en el texto cualquier alusión, incluso indirecta, que se acercara a esta problemática.

El resultado no es sorprendente. La perspectiva de género está totalmente ausente de las inquietudes y los pensamientos de los padres (no había ninguna madre) fundadores de la PAC. La referencia más cercana que se puede encontrar es a la "explotación familiar" agraria. A la luz de nuestros resultados, podríamos caricaturizarla, en conclusiones, como la "explotación de la familia agraria", mujer e hijos incluidos.

Palabras Claves: Política Agraria Común, Política y análisis de género, Conferencia de Stresa

\section{Introducción}

La Política Agraria Común (PAC) es la primera de las grandes políticas europeas. Entorno a ella se crearon y engrasaron los mecanismos comunitarios, desde el cuerpo legislativo de distintos reglamentos hasta las mecánicas de las reuniones entre los ministros y el inicio de las decisiones tomadas por mayoría cualificada. Es por lo tanto un buen reflejo del proceso de construcción comunitario.

En contraposición a la abundante literatura que ha analizado la PAC desde casi todos los ángulos, llama la atención los escasos estudios, todos relativamente recientes, que lo hacen desde una perspectiva de género (Prügl, 2012; Shortall, 2015).

Esta Comunicación es un primer resultado de una línea de investigación recientemente iniciada conjuntamente por los autores, aunque Alicia Langreo llevaba tiempo analizando el papel de las mujeres en la economia de la agricultura y de las zonas rurales de España (véase por ejemplo Langreo Navarro. XXXX). Nos proponemos analizar los principales textos que han marcado la evolución de la PAC desde sus inicios hasta nuestros días en búsqueda de las referencias que se podrían acercar, aunque sea con una visión muy amplia, a la perspectiva de género.

\section{Metodología}

El análisis de texto tiene ya cierta tradición en ciencias sociales (Fairclough, 2003; Wiedemann, 2013). Tampoco son infrecuente, en el campo de la economia y política agraria, los trabajos que recurren así al análisis de textos. Como ejemplo de ello podríamos citar los artículos de Erjavec et al (2008), Sanz Cañada et al (2018) o Mockshell y Birner (2020).

Como primer ejercicio, hemos releído en búsqueda de palabras claves los documentos de la Conferencia de Stresa $^{8}$, que supuso, una vez aprobado el Tratado de Roma, el punto de partida para el desarrollo de la Política Agraria Común (PAC). Hemos empezado nuestro análisis con las palabras "mujer", "mujeres" y "género". El resultado fue la ausencia de toda referencia. A continuación ampliamos la búsqueda con otras expresiones como "familia" o "explotación familiar", resultando la búsqueda sin sorpresa más fructífera.

\footnotetext{
${ }^{8}$ http://aei.pitt.edu/34450/4/A15.pdf
} 


\section{La Conferencia de Stresa}

Entre el 3 y el 12 de julio de 1958 se celebró por lo tanto en la ciudad italiana de Stresa la Conferencia Agrícola de los Estados Miembros de la Comunidad Económica Europea. Fue presidida por el entonces Vicepresidente de la Comisión Europea Sicco L. Mansholt.

Entre los 114 delegados oficiales a la conferencia, solo hemos podido identificar a dos mujeres: una miembro de la delegación alemana, Frau Elisabeth Lünenburger y la Ministra de agricultura de los Países Bajos, Anne Vondeling. Esta era ingeniera agrónoma y miembro del Partido Socialista, habiendo sucedido en el puesto a Sicco Mansholt, del mismo partido, cuando fue nombrado Comisario europeo. Curiosamente, había el mismo número de mujeres que de nobles Barones entre todos los delegados.

Firma del Tratado de Roma: ¡impresiona la presencia femenina!

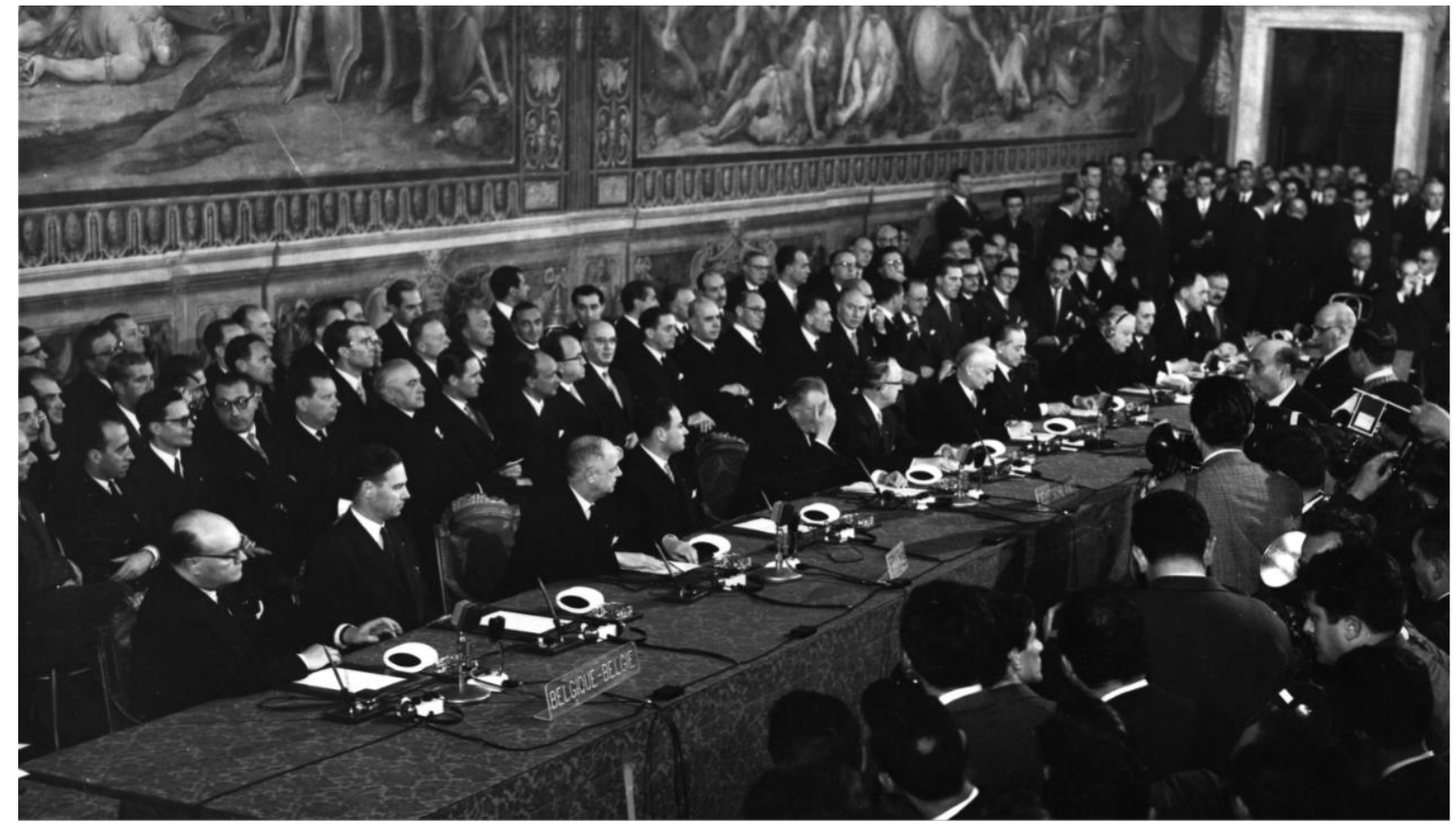

El Presidente de la Comisión, Walter Hallstein, subrayo el "carácter familiar" de la explotación agraria en Europa y la necesidad de mantener a "la familia campesina" subrayando sus valores humanos; los Ministros de la Agricultura alemán, francés, belga y el Comisario Mansholt destacaron el carácter "familiar" de la explotación agraria. Se desmarca de esta unidad el Ministro italiano que introdujo un término algo distinto, el de la "empresa familiar". Son en total siete referencias. En términos comparativos, la palabra “consumidor" aparece también en 7 partes distintas de los documentos de la Conferencia y la palabra "obrero agrícola" seis".

\section{Discusión}

El resultado de este primer ejercicio no es sorprendente. Las dos autoras citadas en la introducción convergen en subrayar que hubo que esperar al Tratado de Ámsterdam, concretamente a su artículo 3 , para que se incorpore entre los objetivos de la Unión Europea la igualdad de género (EC, 2000). En lo referente a la PAC, la política de género apareció específicamente como tal por primera vez en el Reglamento del Desarrollo Rural del 2005.

Se explica por la conjunción de dos factores: el socio-económico por un lado y el político por otro. Los documentos de la Conferencia reflejan la situación de partida de la agricultura de los seis Estados miembros fundadores justo después del final de la segunda guerra mundial. La importancia relativa de la población activa agraria era muy significativa, no solo en Italia $(37,7 \%)$ o en Francia $(28,1 \%)$ sino también en Alemania (20,1\%) Países Bajos (19,5\%) e incluso Luxemburgo (23, 9\%). La única excepción era Bélgica con un $12,5 \%$. 
Esta importante población agraria era el soporte político, y así entramos en el segundo factor, de la democracia cristiana que estaba gobernando (sola o en coalición) en todos y cada uno de los Estados miembros fundadores. Aunque el Presidente Hallstein fue el único que explícitamente se refirió a los valores tradicionales que vinculaban las familias campesinas, este componente ideológico atraviesa claramente a nuestro juicio de los responsables agrarios de la época. Incluso la "revolución silenciosa" (Debatisse, 1963) que vivió el campo europeo a continuación, surgió de las Juventudes Agrarias Católicas (JAC) en Francia, en firme oposición al sindicalismo mayoritario de la época. Marcó el desembarco del "gaullismo" en el vecino país galo, desplazando poco a poco a las élites demócrata-cristianas.

Debemos destacar aquí dos excepciones, la ya mencionada del Ministro italiana que ha introducido el concepto de "empresa" en la discusión y la de la Ministra de los Países Bajos, sin sorpresa mucho más orientada al mercado y señalando por ejemplo las consecuencias negativas que tendría para el equilibrio de los mercados agrarios la fijación de precios agrarios garantizados de manera política, demasiado altos, alejados de la realidad de los mercados. Le apoyo en esto el Ministro francés (país que tenía en estos momentos los precios más bajos (y los costes de producción medios) de los productos agrarios ente el silencio atronador de toda la delegación alemana. .

\section{Conclusiones}

Este primer análisis fue realizado como una manera de comprobar si esta vía de investigación presentaba un cierto interés. El resultado es muy elocuente por el tremendo silencio que vehicula. Como era de esperar, en los primeros textos fundacionales de la PAC, la mujer está totalmente ausente. La explotación familiar agraria (o la explotación de la familia agraria, como acostumbraba a decir en forma de "boutade" Ramón Tamames, mujer e hijos incluidos) en cambio se presenta como el modelo preferido de organización de la agricultura, tanto por razones socio-económicas como políticas.

Las investigadoras Prügl (2012) y Shortall, (2015) afirman que hubo que esperar al año 2005 para que, por primera vez, aparezca la problemática de género en la PAC. Las siguientes etapas de nuestro trabajo consistirán en comprobar si esta afirmación es confirmada por el análisis de texto. Para ello, hemos hecho acopio de todos los textos esenciales publicados por la Comisión hasta la fecha sobre la PAC, su evolución y sus reformas.

\section{Bibliografía}

Debatisse, M. (1963): La révolution silencieuse. Le combat des paysans Calmann-Lévy,

Erjavec K.; Erjavec, E.; Juvančič, L. (2008) : New Wine in Old Bottle: Critical Discourse Analysis of the Current Common EU Agricultural Policy Reform Agenda Sociologia Ruralis Vol 49(1), pp 41-55

European Commission (EC, 2000): Equal Opportunities for Women and Men in the European Union. Annual report 1999. Luxembourg: Publications Office of the European Union,

Fairclough, N. (2003): Analysing Discourse: Textual Analysis for Social Research. Routledge 288 Pages

Mockshell, J.; Birner, R. (2020): Who has the better story? On the narrative foundations of agricultural development dichotomies World Development Volume 135, pp 1-14

Prügl, E. (2012): "The Common Agricultural Policy and Gender Equality" in Abels, G. and Mushaben, J.M.: Gendering the European Union: New Approaches to Old Democratic Deficits Palgrave MacMillan pp 127-145

Sanz Cañada, J.; Belleti, G.; Lagoma, C. (2018): Politics and territorial governance of food consumer groups in the district of Lavapies, Madrid. Journal of Depopulation and Rural Development Studies $n^{\circ} 16$ pp 65-97

Shortall, S. (2015): Gender mainstreaming and the Common Agricultural Policy Gender, Place and Culture 22 (5) pp 717-730

Wiedemann, G. (2013): Opening up to Big Data: Computer-Assisted Analysis of Textual Data in Social Sciences Historical Social Research / Historische Sozialforschung, Vol. 38, No. 4 (146), pp. 332-357 